\title{
AGENDA AMBIENTAL NA ADMINISTRAÇÃO PÚBLICA: COMANDO DE POLÍCIA DO INTERIOR DE PRESIDENTE PRUDENTE - SP: CPI-8
}

\author{
Lucas Prado Osco ${ }^{1}$, Marcos Norberto Boin ${ }^{2}$ \\ ${ }^{1}$ Engenheiro Ambiental, pela UNOESTE, Aluno Especial do Mestrado em Meio Ambiente - UNOESTE. ${ }^{2}$ \\ Docente do Mestrado em Meio Ambiente - UNOESTE. E-mail: lucas prado 123@hotmail.com
}

\section{RESUMO}

O presente trabalho, intitulado "Agenda ambiental na administração pública: Comando de Polícia do Interior de Presidente Prudente - SP: CPI-8" tem por finalidade realizar uma discussão a respeito da Agenda Ambiental na Administração Pública, além de um levantar bibliográfico referente às práticas e políticas ambientais adotadas, em geral, por órgãos e instituições públicas. O enfoque, entretanto, se dá nos setores administrativos da Polícia Militar do Estado de São Paulo, precisamente no Comando de Polícia do Interior 8 (CPI-8) localizado no município de Presidente Prudente - SP. O estudo, portanto, concentrasse na comparação entre as adequações exigidas pela Agenda Ambiental e ao que o Comando de Polícia compromete-se a realizar, além dos recursos necessários para a concretização do atendimento a Agenda Ambiental.

Palavras-chave: Meio Ambiente. A3P. Política Nacional do Meio Ambiente. Política Nacional de Resíduos Sólidos. Gestão Ambiental. Educação Ambiental.

\section{INTRODUÇÃO}

No que se encontra a situação atual do meio ambiente mundial, diversos atores são desafiados a preservar e proteger os recursos naturais, de forma a possibilitar um desenvolvimento social justo, que permita a sociedade atingir metas de boas condições e qualidade de vida a todos os indivíduos (RÊGO; PIMENTA; SARAIVA, 2011). O desenvolvimento justo e igualitário em razão de políticas e práticas que adotem como objetivos a conquista da otimização das condições ambientais no país está atribuída a todos os indivíduos e entidades, sejam estas de qualquer cunho a que se referirem.

Para os autores supracitados, a Constituição Federal de 1988, ao que consagrou o meio ambiente, seja este ecologicamente equilibrado, como um direito de todos, assim como um bem de uso comum e essencial a qualidade de vida, também atribuiu a responsabilidade de sua conservação e defesa a toda a coletividade. No entanto, não somente a coletividade, a C.F. traz como obrigação da proteção do meio ambiente em sua maior competência ao Poder Público, sendo este o principal responsável pela garantia a todos os cidadãos o direito dos mesmos receberem e conviverem com um meio ecologicamente equilibrado.

Consoante à SMA (Secretaria do Meio Ambiente) a administração pública tem por responsabilidade partilhar de políticas ambientais voltadas no cumprimento de suas normas, 
procurando adotar metas que resultem em estratégias inovadoras as quais repensem os padrões atuais de consumo e produção. Assim, é em razão destas necessidades de que as instituições públicas devem programar iniciativas específicas, desenvolvendo projetos que promovam a discussão sobre o desenvolvimento e adoção política de Responsabilidade Socioambiental do setor público.

Dessa forma, surge a Agenda Ambiental na Administração Pública (A3P), um programa que procura incorporar os princípios da responsabilidade socioambiental nas atividades da administração pública. Este se tornou o principal programa no fomento da elaboração de políticas de gerenciamento socioambiental. Colaborando para que diversos órgãos e instituições públicas das três esferas de governo e âmbito dos três poderes possam, inclusive, serem utilizadas como modelos de gestão socioambiental para os demais segmentos da sociedade.

De acordo com o Ministério do Meio Ambiente (MMA), houve um aumento significativo em relação ao número de órgãos públicos que aderiram formalmente à $\mathrm{A} 3 \mathrm{P}$, por meio do "Termo de Adesão à A3P e/ou por meio da Rede A3P", o MMA se compromete a dar apoio técnico a quaisquer órgãos públicos na inserção da variável ambiental em suas atividades, de forma que compete ao órgão a instituição de uma comissão responsável pelo processo de implementação da Agenda Ambiental.

Segundo o MMA, em 2007 cerca de 400 órgãos públicos estavam inclusos nesta Rede, o que indica de que o Poder Público aos poucos passou a se adequar a política de prevenção de impactos negativos decorridos ao meio ambiente. No eixo temático do programa, devem estar inseridos: as licitações sustentáveis; o uso racional de recursos e combate a todas as formas de desperdício; a gestão ambiental de resíduos e a capacitação continuada de gestores públicos. Dentre as instituições públicas que demonstram interesse em um comprometimento com a elaboração de práticas e diretrizes relacionadas a gestão ambiental adequada dentro do órgão está o Comando de Polícia do Interior 8, que abriga o Batalhão de Polícia Militar e outras unidades de administração militar, ao qual, atualmente, procura atender à exigências da A3P e realizar a implementação de uma política ambiental.

\section{Localização do Comando de Polícia do Interior - 8}

Localizado no oeste do Estado de São Paulo, mais precisamente no município de Presidente Prudente, encontrando-se próximo a uma das entradas da área urbana e abrangendo uma área de aproximadamente $5.500 \mathrm{~m}^{2}$, o Comando de Polícia do Interior - 8 (CPI-8) possui uma 
força policial e organizacional que engloba não só a cidade de Presidente Prudente, como também grande parte da região, sendo responsável pelo policiamento em 21 municípios da região do oeste paulista, abrigando as seguintes companhias: 1므 Cia. em Presidente Prudente; 2a Cia. em Martinópolis; 3a Cia. em Pirapozinho; 4a Cia. em Álvares Machado; 5a Cia. em Presidente Prudente; Cia. PM Força Tática em Presidente Prudente.

\section{MATERIAIS E MÉTODOS}

O trabalho em questão visou elaborar levantamentos bibliográficos a cerca da Agenda Ambiental na Administração Pública, abordando sua construção e elaboração, assim como suas políticas voltadas à administração e responsabilidade ambiental. Também procurou relacionar as práticas de gestão ambiental em instituições públicas, comparando seu desenvolvimento e suas atribuições.

Deve desta forma, se relacionar as diretrizes necessárias para seu gerenciamento e enfatizar as ações de atividades ambientalmente adequadas no Comando de Polícia do Interior 8, ao qual busca enquadrar-se dentro de uma política ambiental no que diz respeito ao tratamento do efluente produzido pela instituição, além dos resíduos sólidos descartados. 0 comprometimento da CPI-8, portanto, está voltado para a concretização e o cumprimento das normas e responsabilidades da instituição perante a legislação ambiental brasileira.

\section{RESULTADOS E DISCUSSÃO}

De acordo com o MMA, a Agenda Ambiental na Administração Pública surgiu no ano de 1999 como parte de um projeto do Ministério do Meio Ambiente, tendo por objetivo a revisão em padrões de consumo e produção, além da adoção de novos referenciais de sustentabilidade ambiental em instituições públicas. Dois anos após a criação do projeto, concretizou-se o Programa Agenda Ambiental na Administração Pública, conhecida por A3P, ao qual procurava sensibilizar gestores públicos para a importância às questões ambientais e auxiliar no empreendimento de programas de gestão ambiental.

A A3P fora, anos depois, incluída no Programa de Educação Ambiental (PPA), tal medida garantiu recursos para que a A3P obtivesse formas de ser efetivamente implantada, tornando-se um novo referencial de sustentabilidade das atividades públicas. Por razão a uma reestruturação do Ministério do Meio Ambiente, a A3P integrou-se ao Departamento de Cidadania e Responsabilidade Socioambiental (DCRS), parte da Secretaria de Articulação Institucional e 
Cidadania Ambiental (SAIC). Este novo arranjo institucional proporcionou a A3P o fortalecimento da mesma, enquanto que a Agenda de Responsabilidade Socioambiental do Governo recebeu maior atenção, promulgando a proposição e o estabelecimento de um novo padrão na responsabilidade em atividades na gestão pública que envolva a gestão ambiental, social e econômica.

Com o surgimento da $\mathrm{A} 3 \mathrm{P}$, diversas instituições públicas receberam apoio para implantação de sistemas gestores socioambiental, além do incentivo necessário para dar inicio a atividades ambientalmente corretas. Segundo a NBR ISSO 14.001/04, que dispõe normas para a gestão ambiental, as organizações de todos os tipos estão preocupando-se cada vez mais em alcançar e demonstrar desempenho socioambiental adequado, sendo este por meio do controle de suas atividades e respectivos impactos, prestando serviço ao meio ambiente que compartilhe com a política, a legislação e seus objetivos ambientais.

Para a implantação de um sistema de gestão ambiental é preciso obedecer a um conjunto de regras das quais atendam ou procuram atender a necessidade da instituição no cumprimento do que exige lei, dentre estes, é preciso estabelecer um comprometimento e uma definição da política ambiental dentro do órgão, buscar a elaboração de um plano para este gerenciamento, programá-lo e operacionaliza-lo, não esquecendo, por fim, da realização da avaliação periódica. No entanto, não somente com a criação de um plano, ou a terceirização deste serviço, é o suficiente para implantar um sistema de gestão ambiental, mas também a zção e incentivo de práticas voltadas para a educação ambiental de todos os envolvidos no processo e na instituição.

A Política Nacional do Meio Ambiente, estabelecida no dia 31 de agosto de 1981, relacionou, dentre seus objetivos, a "compatibilização do desenvolvimento econômico-social com a preservação da qualidade do meio ambiente e do equilíbrio ecológico" (PNMA, Art. 4ํ, I), no qual suas diretrizes deveriam ser formuladas em normas e planos, com vista à orientação da ação dos Governos da União, dos Estados, do Distrito Federal, dos Territórios e dos Municípios, à preservação da qualidade ambiental e manutenção do equilíbrio ecológico.

No que diz respeito à educação ambiental, esta, estipulada pela Lei no 9.795, de 27 de abril de 1999, a Política Nacional de Educação Ambiental, em seu Art. 3. Inciso V, relata que, como parte de um processo educativo amplo, todos os indivíduos tem o direito a educação ambiental, e, de uma forma mais específica, atribui este direito:

V - às empresas, entidades de classe, instituições públicas e privadas, promover programas destinados à capacitação dos trabalhadores, visando 
à melhoria e ao controle efetivo sobre o ambiente de trabalho, bem como sobre as repercussões do processo produtivo no meio ambiente;

O ser humano não vê a si próprio como parte do meio ambiente, portanto não compreende totalmente a necessidade e importância que a natureza tem para com o seu desenvolvimento, assim como os problemas gerados, direta ou indiretamente, pelos impactos ocasionados ao meio. A educação ambiental, portanto, tem por finalidade contribuir para a redução desta distancia entre homem e meio ambiente.

No entanto, a evolução e o desenvolvimento da sociedade e indústria como um todo resultaram não somente na ampliação desta distância entre ser humano e a natureza, como também proporcionaram impactos significativos a ambos. Dentre os impactos, decorrente do aumento da população, bem como da produção e consumo, aquele de maior alvo de diversos debates é justamente a questão dos resíduos. Os resíduos sólidos, gerados por conta do descarte de produtos tornou-se um agravante ambiental, não somente por seu significativo aumento no decorrer das décadas, como também em sua periculosidade no que diz respeito às suas características, estas sendo em sua maioria um potencial poluidor quando descartado de forma inadequada no meio ambiente.

A questão dos cuidados aos resíduos sólidos está relacionada às práticas decorrentes da A3P, aos quais estipulam a responsabilidade de órgãos e instituições perante 0 gerenciamento de seus resíduos, sejam estas por meio da Política Nacional de Resíduos Sólidos (PNRS) ou pela Lei Estadual 14.470/11. A Lei 12.305/10 instituiu a PNRS, embora que estruturada com base na Lei Estadual de Resíduos Sólidos do Estado de São Paulo, Lei no 12.300/05, trouxe a nível nacional a preocupação referente aos resíduos, dispondo em seu caput sobre princípios, objetivos e instrumentos, além de diretrizes relacionadas à gestão integrada e ao gerenciamento de resíduos sólidos, sejam estes incluindo aqueles considerados por perigosos, atribuindo sua responsabilidade aos geradores e ao poder público, juntamente com instrumentos econômicos aplicáveis. A responsabilidade, portanto, está promulgada em seu Art 1으 $\S 1$ ò seguinte imposição:

Estão sujeitas à observância desta Lei as pessoas físicas ou jurídicas, de direito público ou privado, responsáveis, direta ou indiretamente, pela geração de resíduos sólidos e as que desenvolvam ações relacionadas à gestão integrada ou ao gerenciamento de resíduos sólidos. 
Ainda de acordo com a PNRS, em seu Art. 3, Inciso XVI, a conceituação de resíduos sólidos está à seguinte maneira:

[...]material, substância, objeto ou bem descartado resultante de atividades humanas em sociedade, a cuja destinação final se procede, se propõe proceder ou se está obrigado a proceder, nos estados sólido ou semissólido, bem como gases contidos em recipientes e líquidos cujas particularidades tornem inviável o seu lançamento na rede pública de esgotos ou em corpos d'água, ou exijam para isso soluções técnica ou economicamente inviáveis em face da melhor tecnologia disponível[...]

Há, entretanto, uma diferenciação entre a denominação utilizada para resíduos sólidos e a de rejeitos, estes considerados como tudo aquilo que é inservível. A questão, portanto, da gestão e gerenciamento dos resíduos, consoante a PNRS em Art. 20, está sujeito à elaboração de plano de gerenciamento de resíduos sólidos os estabelecimentos comerciais e de prestação de serviços que "[...] gerem resíduos que, mesmo caracterizados como não perigosos, por sua natureza, composição ou volume, não sejam equiparados aos resíduos domiciliares pelo poder público municipal." A PNRS ainda evidencia, em seu Art. 27, de que "as pessoas físicas ou jurídicas referidas no art. 20 são responsáveis pela implementação e operacionalização integral do plano de gerenciamento de resíduos sólidos aprovado pelo órgão competente na forma do art. 24."

A PNRS dispõe de que a contratação de serviços sejam estes de coleta, armazenamento, transporte, transbordo e tratamento ou destinação final dos resíduos sólidos, ou então, de acordo com o caso, a disposição final de rejeitos, não isenta nenhuma das pessoas, físicas ou jurídicas referenciadas em ser Art. 20, da responsabilidade perante os danos ou degradações que vierem a ocorrer resultantes de um gerenciamento inadequado por parte de seus respectivos resíduos ou rejeitos.

Não somente por meio da PNRS que se instituiu a responsabilidade pelo gerenciamento e cuidados referentes aos resíduos, seja este em diversos âmbitos de origem (à exemplo os domiciliares, empresariais, urbanos, rurais, dentre outros) a competência aos seus geradores, houve também a elaboração da Lei Estadual, de no 14.470, criada em 22 de junho de 2011 para o Estado de São Paulo, que reforçou, em seu Art. 1ำ, o comprometimento de órgãos ou entidades da administração pública estadual à separação dos resíduos recicláveis descartados pelos mesmos, na fonte geradora. A destinação poderá ser realizada por associações e cooperativas de catadores de materiais recicláveis, por meio da coleta seletiva solidária, no âmbito da existência de programas e incentivos a essas entidades. 


\section{A A3P no Comando de Polícia do Interior - 8}

O Comando de Polícia do Interior - 8 é uma destas instituições de administração pública, ao qual, devido as suas propriedades e a extensão das mesmas, além do montante de trabalhadores diários, produz um considerável montante de resíduos sólidos. De acordo com trabalhos realizados sobre a produção destes resíduos, o CPI-8 gera, em média, um montante de 16,3 toneladas de resíduos por ano, sendo que aproximadamente 6,4 toneladas são recicláveis e 4 toneladas são orgânicos (Prado, L. P; Melo, V. R. 2012).

Este é um montante considerado significativo quando comparado aos demais resíduos domiciliares, portanto, além do alto índice da produção de resíduos, o CPI-8 é um órgão de administração pública, sujeito as implicações e responsabilidades estabelecidas pela legislação, como também parte integrante do foco da Agenda Ambiental. No caso, o CPI-8 busca o comprometimento não somente com aquilo exigido por lei, como também por uma responsabilidade socioambiental que teve por iniciativa não somente o interesse do setor administrativo da instituição, como também na permissão de pesquisas e estudos referentes à sua produção por grupos de estudantes e professores da Universidade do Oeste Paulista (UNOESTE).

Segundo os autores (Prado \& Melo) o CPI-8 possui algumas politicas de reaproveitamento e reutilização dos resíduos de pneus, provenientes da oficina de viaturas policiais. No entanto, o restante ainda recebe práticas inadequadas quando se quer atingir um comprometimento com o meio ambiente, pois não há uma separação correta dos resíduos, além da carência de uma destinação ambientalmente adequada.

Os projetos a serem realizados no $\mathrm{CPI}-8$, portanto, tem por foco tanto a implantação de um sistema de gestão dos resíduos sólidos, assim como a educação ambiental de todos os trabalhadores envolvidos na instituição. Dentre as práticas adotas pelo CPI-8, estão compromissadas aulas com o intento de educar todo o pessoal envolvido, atribuindo-lhes a responsabilidade não somente em relação à separação de resíduos e rejeitos, como também na manutenção e cuidados sobre os mesmos. Há, além destas práticas, a implementação de um EcoPonto, situado exteriormente ao lado do CPI-8, com a finalidade de armazenar, separadamente, os resíduos produzidos, para que grupos de redes coletoras especificas possam retirá-los com maior facilidade e lhes atribuir uma destinação correta de acordo com suas características específicas. 


\section{CONCLUSÃO}

Este trabalho procurou esclarecer as diretrizes levantadas pela Agenda Ambiental na Administração Pública, evidenciando sua devida importância, histórico, comprometimento e objetivos no auxílio às demais instituições públicas na elaboração e cumprimento de normas e práticas voltadas na implantação de um gerenciamento ambientalmente adequado. Embora que alguns dos órgãos públicos tenham realizado práticas voltadas a esta gestão, além da A3P receber maiores condições na prestação deste auxílio ao longo dos últimos anos, a situação ainda não é favorável, pois muitas das administrações públicas ainda não possuem um sistema de gestão ambiental, como também nem sequer a informação necessária sobre os mesmos.

O CPI-8, no entanto, apesar de ser uma instituição pública que não atenda as exigências da Agenda Ambiental, está ciente e preocupado com a qualificação e em apresentar um sistema ambientalmente correto, principalmente em relação aos cuidados referentes aos seus resíduos sólidos. As práticas adotadas pelo $\mathrm{CPI}-8$, em conjunto com trabalhos de alunos e professores da UNOESTE têm por finalidade conquistar o exemplo de um modelo aos demais Comandos de Policia, atendendo a legislação brasileira e assumindo um compromisso ambiental, elaborando planos para educar todos os envolvidos no processo, como também na separação e destinação ambientalmente correta de seus resíduos sólidos.

\section{REFERÊNCIAS}

ASSOCIAÇÃO BRASILEIRA DE NORMAS TÉCNICAS. NBR 14.001. Sistemas da gestão ambiental Requisitos com orientações para uso. Rio de Janeiro: ABNT, 2004.

BRASIL. Constituição da República Federativa do Brasil. 1988.

BRASIL. Lei no 6.938, de 31 de agosto de 1981. Dispõe sobre a Política Nacional do Meio Ambiente, seus fins e mecanismos de formulação e aplicação, e dá outras providências.

BRASIL. Lei n $^{\circ}$ 9.795, de 27 de abril de 1999. Institui a Política Nacional de Educação Ambiental e dá outras providências.

BRASIL. Lei $\mathbf{n}^{\circ}$ 12.305, de 02 de agosto de 2010. Institui a Política Nacional de Resíduos Sólidos; altera a Lei $n^{\circ}$ 9.605, de 12 de fevereiro de 1998; e dá outras providências.

BRASIL. Ministério do Meio Ambiente. Secretaria de Arcitulação Institucional e Cidadania Ambiental Departamento de Cidadania e Responsabilidade Socioambiental. Comissão Gestora da A3P. Agenda Ambiental na Administração Pública - A3P. 4o Ed. Brasília. 2007.

PRADO, L.P.; MELO, V.R. Proposta de gerenciamento dos resíduos sólidos produzidos no 18을 Batalhão de Polícia Militar do Interior. Trabalho de Conclusão de Curso de Engenharia Ambiental. Universidade do Oeste Paulista. Presidente Prudente, São Paulo. 2012. 
RÊGO, G. S.; PIMENTA, H. C. D.; SARAIVA, V. M. Agenda Ambiental na Administração Pública A3P. Um estudo sobre a potencialidade de aplicação no município de São Gonçalo do Amarante/RN. Instituto Federal do Rio Grande do Norte (IFRN) - Campus Central. 2011.

SÃO PAULO. Lei no 14.470 de 22 de junho de 2011. Dispõe sobre a separação dos resíduos recicláveis descartados pelos órgãos e entidades da administração pública estadual, na forma que especifica. 